\title{
Dechloromethylation of the berberine to berberrubine - tricks to obtain pure product
}

\author{
Viktor Milata, Eva Holúbková \\ Department of Organic Chemistry, Institute of Organic Chemistry, Catalysis and Petrochemistry, \\ Faculty of Chemical and Food Technology, Slovak University of Technology, \\ 81237 Bratislava, Radlinského 9, Slovakia \\ viktor.milata@stuba.sk
}

\begin{abstract}
Berberine (1), as a compound with interesting biological activities, can be modified at various positions to obtain more potent substances. Modifications at position 9 are based on demethylation with simultaneous dechloration resulting in berberrubine. The most frequent process is thermal dechloromethylation and this work describes this method with detailed tricks to obtain almost pure product in high yield.
\end{abstract}

\section{Introduction}

Berberine (1) (Scheme 1) is an isoquinoline alkaloid belonging to protoberberine alkaloids (Nechepurenko 2010). About thousand structurally similar alkaloids with planar isoquinoline skeleton are currently known (Huang 2011).

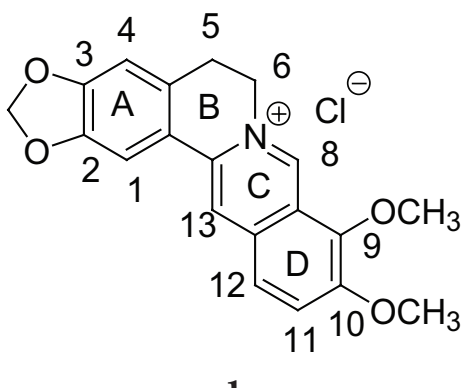

Scheme 1. Berberine.

Berberine can be found in many plants such as Hydrastis canadensis, Coptis chinensis, Berberis aquifolium, Berberis vulgaris or Berberis aristata mostly in crust of their roots, roots or rootstocks obtained by extraction with ethanol and isolated like chloride or hydrogen sulfate, respectively. Berberine shows antibacterial activity against various bacteria, fungi, protozoa, chlamydia or viruses, and it also shows other pharmacological effects (Birdasall, 1997). Very important applications are in the treatment of Alzheimer's disease (Ling, 2012), schizophrenia (Sun, 2013) and HIV (Bodiwala, 2011) due to the inhibition of AChE or topoisomerase I resulting in antiproliferative (antineoplastic, anticancer) (YangBiao, 2013; Lo, 2013; Su, 2013; Xiao, 2012; Zhang, 2012), antimicrobial (Shao-Lin, 2013; Zhan, 2013a), antihyperlipidemic (Peng, 2008) or hypoglycemic activity (Yan-Xiang, 2012).

Most frequent reactions run at positions 2, 3, 9, 10 or on the immonium fragment, e.g. nucleophilic addi- tion (Man, 2001). Reactivity of berberine has been thoroughly summarized by Nechepurenko (2010).

\section{Experimental}

Spectrometer INOVA $300(300 \mathrm{MHz}$, Varian Inc., Palo Alto, CA, USA) was used to measure ${ }^{1} \mathrm{H}$ NMR spectra at RT frequencies. Chemical shifts in $(\delta)-[p p m]$ (parts per million) were referenced to the residual signal of the solvent. Coupling constants $(\mathrm{J})$ are given in $[\mathrm{Hz}]$ with multiplicity: s (singlet), d (doublet), dd (doublet of the doublet), $\mathrm{t}$ (triplet), q (quartet), q (quintet) and $\mathrm{m}$ (multiplet). Tetramethylsilane was used to calculate ${ }^{1} \mathrm{H}$ chemical shift scales and it was correctly referenced using the (residual) solvent signals (2.50 and $39.52 \mathrm{ppm}$ for DMSO).

All reagents (incl. berberine chloride) and solvents were purchased from Sigma-Aldrich ${ }^{\circledR}$ (Darmstadt, Germany), Alfa-Aesar ${ }^{\circledR}$ (Ward Hill, MA, USA), Fluka ${ }^{\circledR}$ (Buchs, Switzerland) and Mikrochem ${ }^{\circledR}$ (Pezinok, Slovakia). Solvents were purified and/or dried using standard laboratory methods and stored over molecular sieves $(4 \AA)$. Column chromatography was performed using silica gel Nomasil-40-63 m (VWR ${ }^{\circledR}$, Randor, PA, USA) and a suitable eluent according to TLC. Reaction progress was monitored by thin layer chromatography on Silufol or Alufol plates (Merck®, Darmstadt, Germany) with a UV indicator at $\lambda=254 \mathrm{~nm}$.

Melting points (m. p.) of the prepared compounds were determined on a Boetius micro hot stage using a digital thermometer TD 121 (VWR $\AA$, Randor, PA, USA) and are uncorrected.

\section{5, 6-Dihydro-9-hydroxy-10-methoxybenzo[g]-} 1,3-benzodioxolo[5,6-a]quinolizinium (berberrubine) A sample of $2.0 \mathrm{~g}(2.3 \mathrm{mmol})$ of berberine (1) was heated without any solvent under vacuum and magnetic stirring to $200{ }^{\circ} \mathrm{C}$ for 40 minutes. During heat- 
ing, yellow berberine powder slowly turned to deep red-brown-black matter of the crude product. Yield was around $1.54 \mathrm{~g}$ of raw berberrubine. Recrystallization from methanol - ethanol 1:1 mixture gave almost analytically pure product.

${ }^{1}$ H NMR: $\left(\mathrm{CD}_{3} \mathrm{OD}\right) \delta 9.28$ (s, 1H, H-8), 8.70 (s, 1H, H-13), $7.54\left(\mathrm{t}, 1 \mathrm{H},{ }^{3} \mathrm{~J}_{\mathrm{HH}}=8.04 \mathrm{~Hz}, \mathrm{H}-12\right), 7.49(\mathrm{~s}$, $1 \mathrm{H}, \mathrm{H}-1), 6.91\left(\mathrm{~d}, 1 \mathrm{H},{ }^{3} \mathrm{~J}_{\mathrm{HH}}=7.60, \mathrm{H}-11\right), 6.85(\mathrm{~s}$, $1 \mathrm{H}, \mathrm{H}-4), 6.04$ (s, 2H, H-2'), $4.60\left(\mathrm{t}, 2 \mathrm{H},{ }^{3} \mathrm{~J}_{\mathrm{HH}}=5.32\right.$, H-6), 3.89 (s, 3H, H-10'), $3.12\left(\mathrm{t}, 2 \mathrm{H},{ }^{3} \mathrm{~J}_{\mathrm{HH}}=5.46\right.$, H-5)

${ }^{13}$ C NMR: $\left(\mathrm{CD}_{3} \mathrm{OD}\right) \delta 149.5\left(\mathrm{C}-13^{\prime}\right), 149.4(\mathrm{C}-9)$, 148.0 (C-10), 145.9 (C-8), 134.2 (C-2), 132.2 (C-3), 129.2 (C-12'), 122.6 (C-8 $), 121.4$ (C-4'), 120.1 (C-13"), 118.3 (C-12), 107.7 (C-11), 107.1 (C-13), 104.4 (C-4),101.8 (C-1), 56.9 (C-2), 55.2 (C-10), 54.1 (C-6), 27.5 (C-5)

\section{Results and Discussion}

Berberrubine alone has interesting properties. It behaves as a fluorescent chemosensor of alkanes with an almost constant response regardless of the alkane chain length (Delgado-Camón, 2015). Because many biological activities are related to structural modifications (Xiao, 2017) at position 9 (Liu, 2017, Xiao 2018), some 9-substituted derivatives were prepared (Milata, 2019). Dechloromethylation of the starting berberine (1) selectively occurring at position 9 is the key step leading to derivatization of this position. Therefore, a number of berberrubine preparations are known (Iwasa, 1996; Lo, 2013; Basu, 2012; Zhan, 2013a, 2013b), including microwave one (Liu, 2014; Delgado-Camón, 2015; Das, 2002), but these procedures are not recommended to be used with larger batches (more than $1 \mathrm{~g}$ ). Due to the volatility of methylchloride, most of these reactions proceed under vacuum. In 2015, quantum chemical calculations have been published (Delgado-Camón, 2015, Scheme 2).

DFT calculations explain that the observed selectivity depends on the electron delocalization capability and the selectively demethylated species $\mathbf{2 a} / \mathbf{2 b}$ are in oxo-enol tautomeric equilibria. Thus, a simple mechanism of berberine (1) dechloromethylation to berberrubine (2) was proposed (Scheme 3).

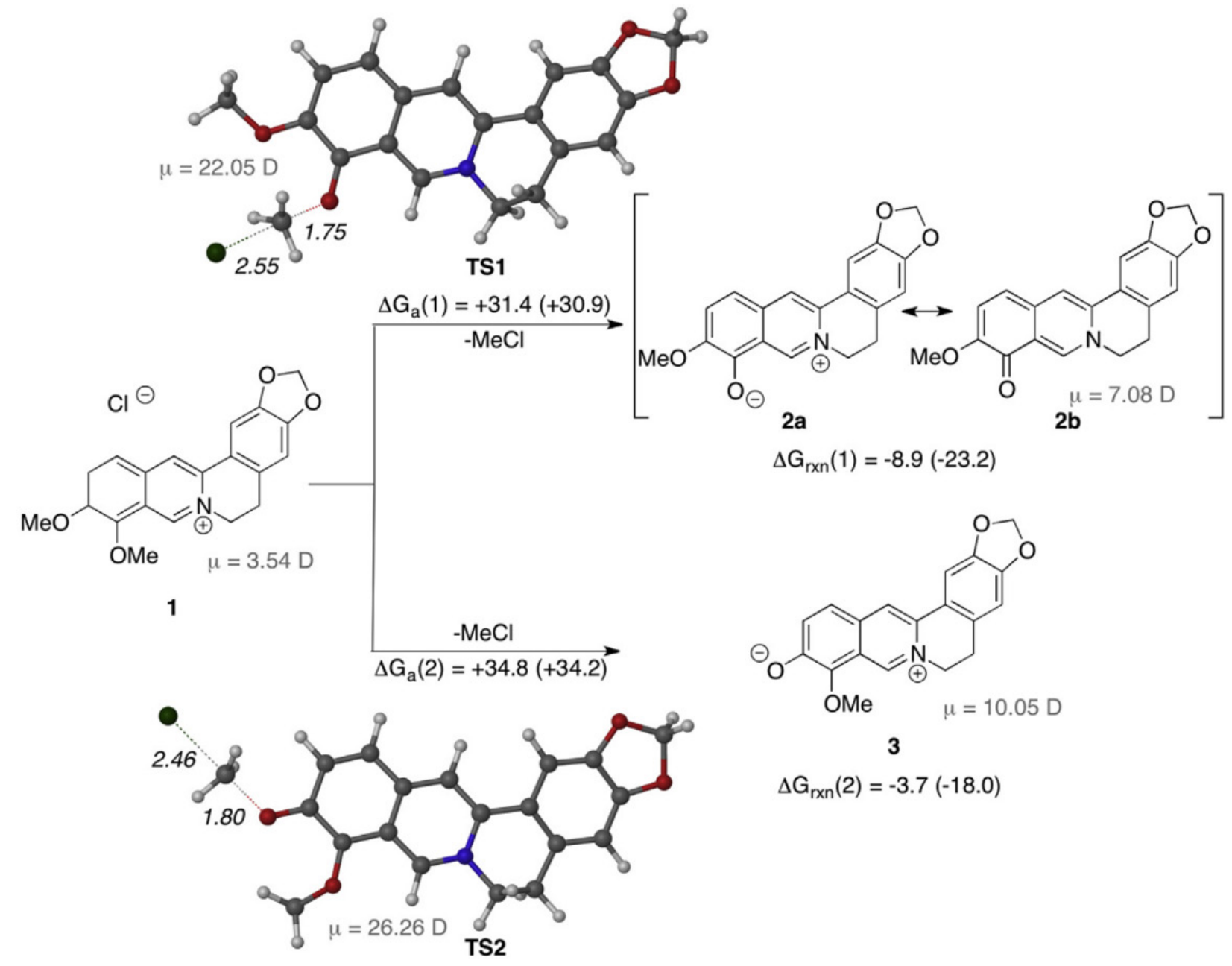

Scheme 2. DFT calculations of the dechloromethylation of 1. Reproduced from Delgado-Camón 2015 with permission of Elsevier Ltd. 
<smiles></smiles>

Scheme 3. Proposed mechanism of berberine (1) dechloromethylation to berberrubine (2).

The crucial step was optimized also under microwave irradiation in an open vessel, closed vessel and in a closed vessel under vacuum $(1.6 \mathrm{kPa})$ but the obtained yields were not higher than $80 \%$ and, according to our experience, yields close to the quantitative one are not real (Delgado-Camón, 2015). Classical procedures have proved to be the most efficient, economical and simple. The best results were obtained in a round bottomed flask for a $2 \mathrm{~g}$ batch with the volume of $100 \mathrm{ml}$ (Fig. 1a). An Apolon (pear-shaped) flask might be better but one with an NZ 29 ground was not at disposal. A tear drop-shaped flask is not as advantageous and the last one, which can be used under vacuum - heartshaped flask, is totally unsuitable considering the following mechanical stirring.

The starting deep yellow berberine (1) is a voluminous, mobile, lightweight powder and $2 \mathrm{~g}$ of it is the optimum quantity for each run: the flask is connected to vacuum $(1.6 \mathrm{kPa})$. Higher vacuum gives does not result in better yields or faster reaction; on the contrary, when the flask is closed and vacuum is applied, the dust outlet at $1.6 \mathrm{kPa}$ is low (estimated approx. 2-3\% - see Fig. 1a), at higher vacuum, the dust outlet is much higher (perhaps it is influenced by sublimation).

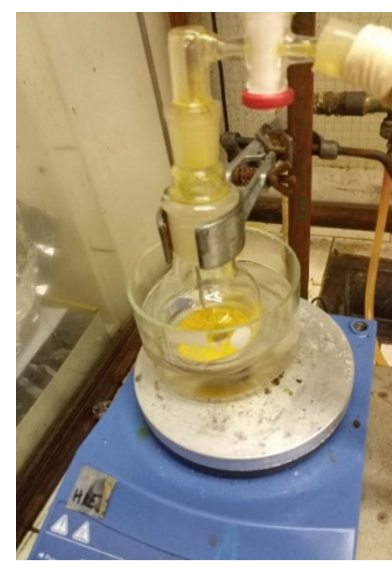

a)

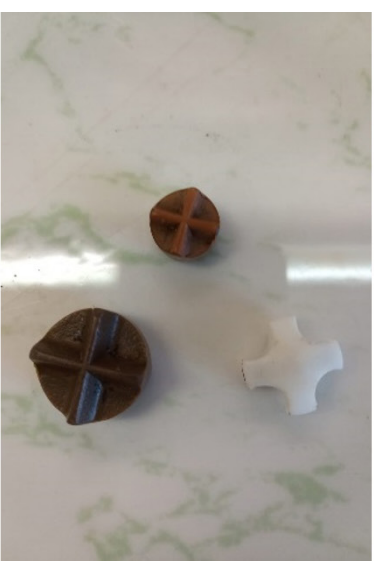

b)

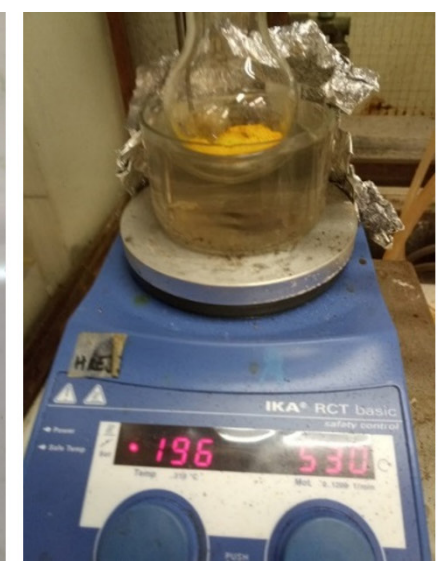

c)

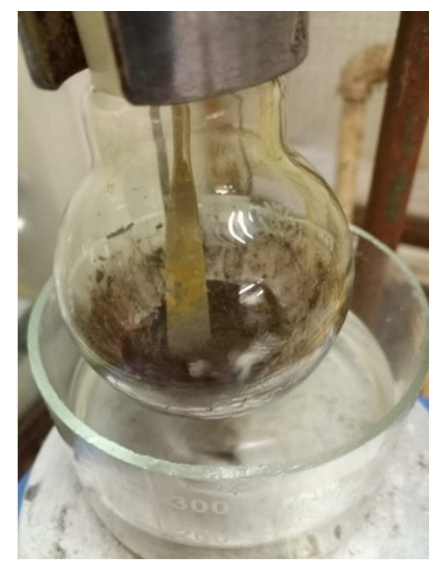

d)

Fig. 1. a) Apparatus for effective preparation of 1, b) Mag. stirrers, c) First stop of heating of 1, d) Final product. 
Recrystallization was carried out from a mixture of ethanol:methanol (1:1); $1.57 \mathrm{~g}$ of raw 1 was refluxed in a sufficient amount of solvent (about $18 \mathrm{ml}$ ). After cooling, the separated ruby-red colored crystals were filtered off and washed with cold ethanol (berberrubine is insoluble in ethanol, contrary to methanol). After vacuum drying $\left(1.6 \mathrm{kPa}, 40{ }^{\circ} \mathrm{C}, 1 \mathrm{~h}\right)$, an analytical sample of berberrubine (2) (usually $1.25 \mathrm{~g}, 62.5 \%$ ) with m.p. 275-279 ${ }^{\circ} \mathrm{C}$ was obtained.

\section{Acknowledgement}

This work was financially supported by the Science and Technology Assistance Agency under the contract No. APVV-17-0513.

\section{References}

Basu A, Jaisankar P, Kumar SG (2012) Bioorg. Med. Chem. 20: 2498-2505.

Birdasall TC, Kelly GS (1997) Alt. Med. Rev. 2: 94-103. Bodiwala HS, Sabde S, Mitra D, Bhutani KK, Sigh IP (2011) Eur. J. Med. Chem. 46: 1045-1049.

Das B, Srinivas KVNS (2002) Synth. Commun. 32: 3027-3029.

Delgado-Camón A, Jarne C, Cebolla VL, Larrañaga O, de Cózar A, Cossio FP, Vara Y, Domínguez A, Membrado L, Galbán J, Garriga R (2015) Tetrahedron 71: 6148-6154.

Huang Z, Zeng Y, Lan P, Sun PH, Chen WM (2011) Mini. Rev. Med. Chem. 11(13): 1122-1129.

Iwasa K, Kamigauchi K, Ueki M, Taniguchi M (1996) Eur. J. Med. Chem. 31: 469-478.

Ling $\mathrm{H}$, Tao $\mathrm{S}$, Wenjun $\mathrm{S}$, Zhonghua L, Yang $\mathrm{S}$, Feng H, Xinshu L (2012) Bioorg. Med. Chem. 20: 3038-3048.

Liu L-X, Yuan X, Gao Y, Zhou D-B, Li W-M, Tianran Chanwu Yanjiu Yu Kaifa (2014) 26(3): 427-430.
Lo Ch-Y, Hsu L-Ch, Chen M-S, Lin Y-J, Chen L-G, Kuo Ch-D, Wu J-Y (2013) Bioorg. Med. Chem. Lett. 23: 305-309.

Man S, Potáček M, Nečas M, Žák Z, Dostál J (2001) Molecules 6: 433-441.

Milata V, Švédová A, Barbieriková Z, Holúbková E, Čipáková I, Cholujová D, Pánik M, Jantová S, Brezová V, Čipák L' (2019) Int. J. Mol. Sci. 20(9): 2169-2187.

Nechepurenko IV, Salakhutdinov NF, Tolstikov GA (2010) Chem. Sust. Devel. 18: 1-23.

Peng Y, Dan-Quing S, Ying-Hong L, Wei-Jia K, YanXiang W, Li-Mei G, Shu-Yu L, Rui-Qiang C, Jian-Dong J (2008) Bioorg. Med. Chem. Lett. 18: 4675-4677.

Shao-Lin Z, Juan-Juan C, Guri LVD, Bo F, Xiang-Dong Z, Rong-Xia G, Cheng-He Z (2013) Bioorg. Med. Chem. Lett. 23: 1008-1012.

Su T, Xie S, Yan J, Huang L, Li X (2013) Bioorg. Med. Chem. 21: 5830-5840.

Sun H, Zhu L, Yang H, Qian W, Guo L, Zhou S, Gao B, Li Z, Zhou Y, Jiang H, Chen K, Zhen X, Liu H (2013) Bioorg. Med. Chem. 21: 856-868.

Xiao D, Liu Z, Zhang S, Zhou M, He F, Zou M, Peng J, Xie X, Liu Y, Peng D (2017) Mini-Reviews Med. Chem. 17: 1424-1441.

Xiao N, Chen S, Ma Y, Qiu J, Tan J-H, Ou T-M, Gu Z-S, Li D (2012) Biochem. Biophys. Res. Commun. 419: $567-572$.

Yan-Xiang W, Wei-Jia K, Ying-Hong L, Sheng T, Zheng L, Yang-Biao L, Yong-Qiang S, Chong-Wen B, Jian-Dong J, Dan-Qing S (2012) Bioorg. Med. Chem. 6552-6558.

Yang-Biao L, Wu-Li Z, Yan-Xing W, Cai-Xia Z, Jian-Dong J, Chong-Wen B, Sheng T, Ru-Xian C, Rong-Guang S, Dan-Qing S (2013) Eur. J. Med. Chem. 68: 463-472.

Zhan L, Chang J-J, Damu GLV, Fang B, Zhou X-D, Geng R-X, Zhou C-H (2013a) Bioorg. Med. Chem. Lett. 23: 1008-1012.

Zhan L, Chang J-J, Zhang S-L, Damu GLV, Geng R-X, Zhou Ch-H (2013b) Bioorg. Med. Chem. 21: 4158-4169.

Zhang L, Li J, Ma F, Yao S, Li N, Wang J, Wang Y, Wang X, Yao Q (2012) Molecules 17: 11294-11302. 